\title{
Retail coffee business analysis and industry development research based on Starbucks business model
}

\author{
Jidi Cao ${ }^{1}$, Rui Qiu ${ }^{1, *}$ \\ ${ }^{1}$ Business School, Sichuan University, Chengdu, 610064, P. R. China
}

\begin{abstract}
As retailing is the customer-based business and easy to observe, standing in this area will be a good view to see the wisdom of business management to change the world. After choosing retail coffee industry as topic, by which Starbucks represented, we will have two major contents to see the knowledge and the insight of business management and industry development research based on Starbucks business model. They are project selection and analysis of Starbucks involving industry development. The Starbucks business model analysis involves product management, customer relationship management, culture and brand management, and ethical marketing and corporate social responsibility. There are still some risks imbedded in the business model. Risks should be estimated and evaluated in advance, whilst project managers need to follow risk mitigation strategies.
\end{abstract}

\section{Introduction}

All on-premises, off-premises, and online sales of hot, iced, and instant coffee, as well as sales of coffee beans and ground coffee, are included in the retail coffee business [1,2]. Sales from all main retail channels, including specialised stores, general merchandisers, and online merchants, are included in this market $[3,4]$. Global coffee consumption was estimated at USD 150.11 billion in 2018 and is expected to reach USD 203.85 billion by 2024. As of the end of 2019, the worldwide coffee market is expected to expand at a $5.5 \%$ compound annual growth rate over the following five years. As one of the world's most popular drinks and a significant source of caffeine, coffee remains an integral part of society's daily routine $[5,6]$.

The European market is one of the main destinations for speciality coffee $[7,8]$. Commercially, coffee is a commodity, but many European businesses are promoting it as an artisanal product [9]. The port-covered ports of Antwerp, Bremen, Hamburg, Genoa, Le Havre, and Trieste contribute to Europe's coffee supply [10]. European supermarkets are the primary distribution centre for coffee, whether in the form of capsules or single-origin variations $[11,12]$. It has enabled them to remain sustainable and provide the customers what they want. Notably, even traditional roasters have jumped into the retail coffee industry, with offerings that are even more particularised for their customers [13]. Also, this tendency has contributed to pricing disparities and has proven difficult for exporters because of the market segmentation.

\section{Project selection}

There are four aspects need to measure and evaluate when select the project to make sure we find the right direction.

Firstly, risk, the unpredictability of firm is low for retail coffee. The quality and safety of beverage like coffee is guaranteed within mature production supply chain and production process. The technical issues cannot be a major problem since not many customers chase extraordinary taste when come to retail stores, otherwise, the focus should be customer experience beyond coffee itself.

The second screening criteria is market potential. Although coffee is much more popular in Europe and America than in Asia-Pacific areas, the potential demand needs to be found and customers need to be educated in new continents across the sea. The project will dig into customer behaviour to know how to turn customer demand into tangible outcomes and intangible interests. Indeed, there is large space to develop the business in emerging market like China, India, and other developing countries.

The third standard is internal operating. Because the business model in retail coffee is close in different areas, which is supported by similar supply chain from different vendors. And the process basically includes: Purchase of coffee pods, machine and other materials; Operating for different kinds of products as handmade or automated; Shipping to supermarket, coffee stores and other sale channel; Packing, shipping, or serving buyers to fulfil obligation.

Brand effect is the fourth consideration. From a long

history, a success in one country can be duplicated in another land, especially in current globalization, where

${ }^{*}$ Corresponding author: qiuruicd@scu.edu.cn 
customers' reliance and dependence play a greater role than ever before. With the help of information share and IT transforming, prestige and brand can be powerful weapon to expand the new market and lead customer behaviour in retailing.

Meeting criteria, detailed project management of Starbucks will give us a picture how it takes over the market and change the world in the next section.

\section{Analysis of Starbucks business model}

A project is a temporary undertaking aimed at creating a unique product, service, or outcome. Some characteristics can be found: projects are one-time procedures that are difficult to manage; the only thing that stands between projects is money, time, and resources; a project is created to achieve a certain objective or set of objectives. When it comes to projects, they are customer focused.

The project of coffee store contains diverse resource, which is political, economic, social, and technological, such as fixed investment, human resource, marketing, etc. Demand for certified coffee goods, growing use of singleserve coffee brewing devices, and continuous innovation among the leaders in the coffee industry are three important variables that influence the market.

According to the statistics from International Coffee Organization [14], the global coffee consumption increased by $6.12 \%$ from 2016 to 2018 . However, the strict epidemic prevention policy in 2019 leads to the suspension of coffee shops, where the global coffee consumption decreased from 168.49 million bags in 2018 to 164.53 million bags in 2019 , and coffee consumption is expected to go up at 166.63 million bags in 2020 , as shown in Fig. 1.

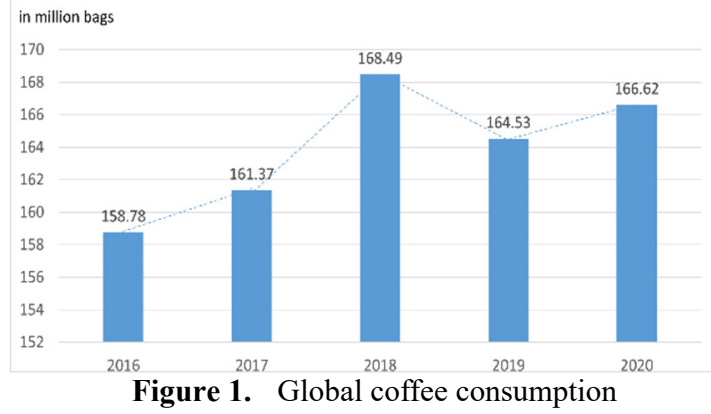

Since its establishment in 1971 in Seattle, Washington, Starbucks has completed the expansion of its 10000 stores in 2006 and 30,000 stores in 2019 respectively, as shown in Fig. 2 [15]. There are some reasons for Starbucks' success. Firstly, Starbucks creates brand effect with highquality products, and widely use Starbucks logo in packaging; Secondly, stores location with high flow and high exposure were selected to effectively enhance brand awareness; Thirdly, it created a stable and fashionable decoration style, and the strong brand effect helps with the rapid expansion.

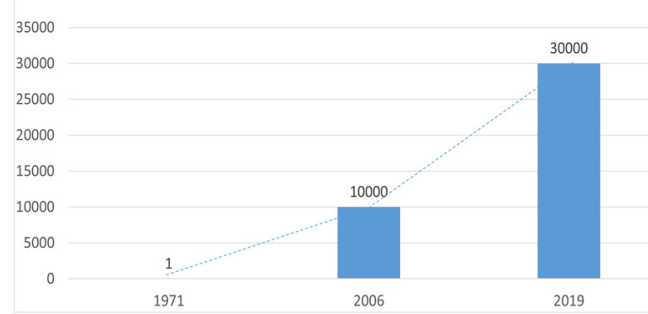

Figure 2. Store expansion of Starbucks

The business model of Starbucks is designed to get more market share and shareholders return, in which limited by time, cost, performance and customer acceptance, so we called quadruple constraint of project success.

Since goals of project include ensuring client satisfaction and meeting financial objectives within a specified budget, this article will focus on marketing management of Starbucks, which includes product management, customer relationship management, culture and brand management and ethical marketing and corporate social responsibility.

\subsection{Product management}

Essential to build client loyalty is providing a firm with stability, regularity of demand, and resistance to competition within a market.

For different groups, Starbucks has targeting and flexible strategy. 18-to-40-year-old demographic provided the chance for various tactics; the shop offers high-quality coffee for hard-to-consume customers while maintaining a premium brand image. Following the trend of people's lifestyle is also an important product strategy. As the development of artificial meat, Starbucks launched meatless breakfast to compete with other retail restaurants like McDonald's. Starbucks is trying to boost night-time sales because most people don't purchase coffee before bed, like beer or wine. Refer to Figure 3, which depicts the strategic move that may be classified as product development or even diversification.

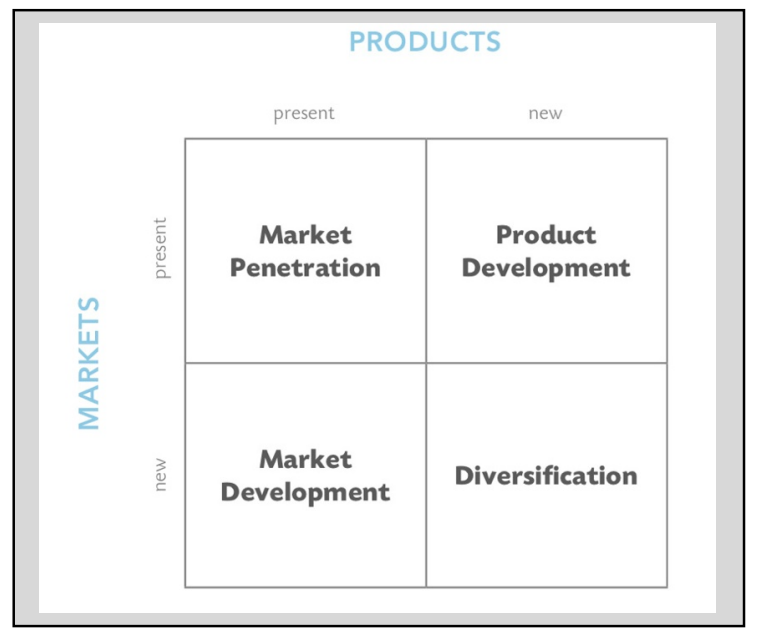

Figure 3. Ansoff Matrix.

The sales from beverage are still the major source, which accounts for more than $60 \%$ total sales in the past eight years, as shown in Fig. 4 [16]. The average annually 
growth of sales is close to $10 \%$ from 2013 when Starbucks take the spearhead in the retail coffee industry, indicating the robust expansion and potential sustainability of the company. Besides, the structure of sales segmentation is comparably stable even under the pressure of COVID-19, which implicate the diversification may happen within beverage areas, not in the whole product matrix.

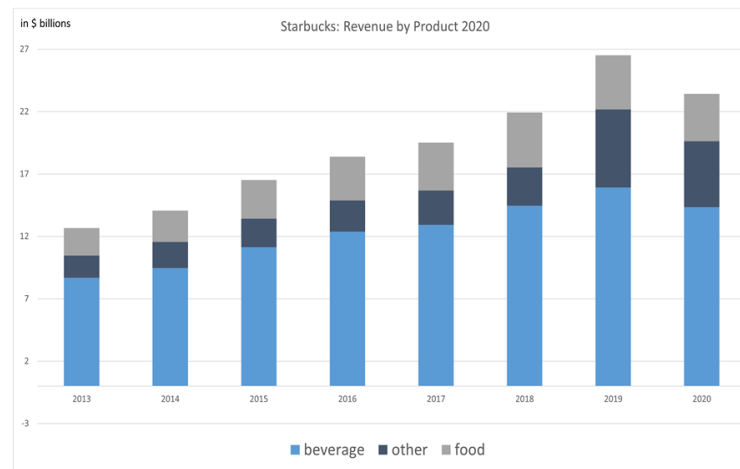

Figure 4. Sales segmentation of Starbucks

Starbucks always promote their concepts of thirdparty space, to which provide comfortable space for people with social needs and workplace requirement, and this could be a personalized experience since the Internet distances us from real social activity when marking us closer online. People go to Starbucks aim to acquire private time and space to settle down for chats or work outside workplace and home, escaping from repeated life routine between family and work.

Additionally, the business prioritises thoroughness. for instance, consumers know the sources of their coffee or tea because of fair-trade groups that do regular audits on the coffee production process at Starbucks When it comes to environmental sustainability, designs are the most powerful component. Customers have written their name on the coffee cup, which indicates that the coffee shop values and supports its customers.

\subsection{Customer relationship management}

From analysis of customer behaviour, maintaining the relationship and adapting trend with customers are the key to carry sustainable business and gain long-run profit.

The Starbucks mobile application which enabled consumers to pay at Starbucks processed almost 20 million transactions in total over the course of a year. Social media is a component of Starbucks' customer relationship management, since they use websites such as Twitter and Facebook to socially interact with its users.

Cognitive loyalty is challenging to adopt, and therefore Starbucks usually rewards consumers with their loyalty cards in order to boost customer loyalty. The gold member reward package is also available.

By collecting data on what items customers purchase, and which locations they visit, Starbucks gains new insights about its customers. These offers will be used for a proposition: consumers will get personalised offers with their favourite goods, which will make them feel as though they are saving money.

\subsection{Culture and brand management}

Culture affects company success through driving values, conventions, traditions, and behavioural expectations within the workplace environment. Starbucks' principles have stayed constant since the company's inception in 1971. Their goal statement is as follows: "To inspire and nurture the human spirit - one person, one cup, and one neighbourhood at a time." At Starbucks, the company culture penetrates all parts of the business, including franchisees and licensees. The atmosphere within company-owned Starbucks locations is particularly visible for employees. Coffee workers' practises and their interactions with customers are indications of the company's corporate culture. Cultural distinctiveness, which includes Dunkin' Donuts and McDonald's, is part of the coffee shop company's unique and welcoming atmosphere. Despite economic changes and industryspecific developments, Starbucks has an organisational culture that connects to brand development and worldwide expansion of the franchise and licencing network.

\subsection{Ethical marketing and corporate social responsibility}

A successful project team should possess a strong sense of purpose, productive interdependence, cohesion, trust, excitement, and a results-oriented mindset. Employees are referred to as "partners," which fosters a feeling of belonging to a community in which management relationships are more open than in a traditional employee role.

Consumers now days look for ethical behaviour, and customers are ready to pay more for additional service even if it is possible to get same quality for less. An individual's belonging in a group is one of Maslow's hierarchy of needs, since when people feel as if they belong, they gain happiness.

Overall, in 2014 Starbucks was included as a prize for its local farmer assistance programme, coffees ethical supplies, and the environmentally friendly shops and materials utilised in 2014 "World's Most Ethical Companies." Starbucks aspires to have all of its coffee ( $95 \%$ in 2013 ) sourced ethically by 2015 , and they aim to use this mission to influence global standards and improve farmer livelihoods. The shops are constructed entirely of recycled materials, and the cups used to serve drinks are likewise 100 percent recyclable. Clearly, the pleasant atmosphere, along with the development of strong ethical ideals, has boosted Starbucks sales.

All in all, Starbucks improve the performance and brand equity through this ethical approach which focuses on social effect, rather than through tremendous investment in advertising and publicity. Words of mouth is self-evident advertisement, gaining more credit and positive image, and it is also a lesson that modern enterprises are taught in era of instant information. 


\section{Conclusions}

Starbucks is a successful project because looking at the results of project, the company has outstanding financial performance and operating output. We can learn more than strategy and theory form the business model to enhance our future projects. Then we view Starbucks through analysis of marketing management and industry development.

In product management, Starbucks has agile strategy targets at different consumer groups with respective demand, even new product like wine and beer is launched as product development. More than coffee, the company focuses on customer in-store experience, which makes its position in retail coffee untouchable. The service includes the friendly environment, personalized detail, visible hand-made process, etc. The comprehensive experience in Starbucks is unforgettable and cannot easily replaced by other peers, providing additional brand equity and business image. Reviewing customer relationship management, the company used fidelity card, social media, and mobile app to get involved in customers' daily life and to promote products. This maintains a healthy connection with customers and increase the stickiness of service. From culture and brand management, Starbucks seek for methods to keep a positive image in front of public and make people think about high quality product, delicate service, and medium-top class behaviour, triggering the humanity desire for sense of belonging. Ethical management and corporate social responsibility are innovative ways to help Starbucks become the leader. Invisible advertising connected with CSR is the approach that touches people's mind and feelings, which is more effective and economical than conventional advertising. This can be informative template for entrepreneurs and project managers to rethink about marketing and publicity in the execution phase of the whole project life cycle.

However, there is still some risks imbedded in the business model. Some boycott in the last five years happened as the price of Starbucks is much higher than competitors, and it also involved in tax evasion in U.K. in early years that push the stock price at the brink. Risks should be estimated and evaluated in advance, whilst project managers need to follow risk mitigation strategies, to accept, minimize, share, and transfer the uncertainty or loss whenever it happens.

\section{Acknowledgments}

This research was supported by the National Natural Science Foundation of China under Grant No.71901157, the China Postdoctoral Science Foundation under Grant No. 2019M660244, and the Soft Science Program of Sichuan Province under Grant No. 2020JDR0099.

\section{References}

1. Santoro, G., Fiano, F., Bertoldi, B, \& Ciampi, F. (2019). Big data for business management in the retail industry. Management Decision, 57(8), 19801992.
2. Wei, S. (2021). Analysis of marketing innovation under the new retail mode-taking "Luckin coffee" as an example. E3S Web of Conferences, 235(17), 01074.

3. Hardesty, D. M., Goodstein, R. C., D Grewal, Miyazaki, A. D., \& Kopalle, P. (2014). The accuracy of scanned prices. Journal of Retailing, 90(2), 291300 .

4. Anthara, I., \& Salim, E. (2019). Probability analysis of coffee sales using Markov theory. IOP Conference Series Materials Science and Engineering, 662, 062006.

5. Nolan, L. (2001). The world's favorite beveragecoffee-and health. Journal of Herbs Spices \& Medicinal Plants, 8(2), 119-159.

6. Simon, B. (2011). Not going to Starbucks: Boycotts and the out-scouring of politics in the branded world. Journal of Consumer Culture, 11(2), 145-167.

7. Berger, A. N. (2003). The efficiency effects of a single market for financial services in Europe. European Journal of Operational Research, 150(3), 466-481.

8. Khodakarami, N., Dirani, K., \& Rezaei, F. (2018). Employee engagement: finding a generally accepted measurement scale. Industrial and Commercial Training, 50(6), 305-311.

9. Grinshpun, H. (2013). Deconstructing a global commodity: coffee, culture, and consumption in japan. Journal of Consumer Culture, 14(3), 343-364.

10. Quader, S. (2013). Drinking coffee in Europe: A demographic analysis. Social Science Electronic Publishing, 1-34.

11. Liang, S., Gemming, L., L Wellard, O., \& Rangan, A. (2019). Comparison between serving sizes of cakes and muffins sold in Australian supermarkets and coffee shop chains. Nutrition \& Dietetics, 76(3), 284289.

12. Marty, L., Evans, R., Sheen, F., Humphreys, G., \& Robinson, E. (2021). The energy and nutritional content of snacks sold at supermarkets and coffee shops in the UK. Journal of Human Nutrition and Dietetics. https://doi.org/10.1111/jhn.12880

13. Feuerstein, S. (2002). Do coffee roasters benefit from high prices of green coffee? International Journal of Industrial Organization, 20(1), 89-118.

14. International Coffee Organization. (2020). Trade Statistics Tables. https://www.ico.org/. (Accessed 26 June 2021)

15. Knoema. (2021). Number of Starbucks Stores Globally.

https://cn.knoema.com/infographics/kchdsge/numbe r-of-starbucks-stores-globally-1992-2021. (Accessed 26 June 2021)

16. Business Quant. (2020). Starbucks: Revenue by Product 2020. https://businessquant.com/starbucksrevenue-by-product. (Accessed 26 June 2021) 